Stefan R. Florentinus - Merete W. Nielsen

Liset van Dijk - Hubert G. M. Leufkens

Ebba Holme Hansen · Eibert R. Heerdink

\title{
Patient characteristics associated with prescribing of a newly introduced drug: the case of rofecoxib
}

Received: 27 September 2004/ Accepted: 4 January 2005/Published online: 11 March 2005

(C) Springer-Verlag 2005

\begin{abstract}
Objective: To identify socio-demographic characteristics of the first patients receiving a new drug-rofecoxib.

Outcome measurement: Patients starting on rofecoxib or another non-steroidal anti-inflammatory drug (NSAID) and who had not received any NSAIDs the 90 days prior to starting.

Results: Starting on rofecoxib was associated with an increasing age (OR in age 80 years and older $8.7 ; 95 \%$ CI 6.7-11.2), a poor self-perceived health $(\mathrm{OR}=2.4$; 95\% CI 1.8-3.3), female gender $(\mathrm{OR}=1.4 ; 95 \%$ CI $1.2-$ $1.6)$, private insurance $(\mathrm{OR}=1.3 ; 1.1-1.5)$ and previous acetaminophen use $(\mathrm{OR}=1.3 ; 1.1-1.7)$.

Conclusion: This study noted that specific patient characteristics were associated with getting rofecoxib prescribed shortly after marketing. General practitioners should be aware of selectively prescribing new drugs to specific patients because it may place patients at unintentional and avoidable risk.
\end{abstract}

S. R. Florentinus $\cdot$ M. W. Nielsen

H. G. M. Leufkens · E. R. Heerdink $(\varangle)$

Department of Pharmacoepidemiology \& Pharmacotherapy,

Utrecht Institute for Pharmaceutical Sciences,

80082, 3508 TB Utrecht,

The Netherlands

E-mail: E.R.Heerdink@pharm.uu.nl

Tel.: +31-30-2537324

Fax: $+31-30-2539166$

M. W. Nielsen · E. H. Hansen

Department of Social Pharmacy,

The Danish University of Pharmaceutical Sciences,

Copenhagen,

Denmark

L. van Dijk

Netherlands Institute for Health Services Research,

Utrecht,

The Netherlands

E. H. Hansen

FKL - Research Centre for Quality in Medicine Use, Denmark
Keywords Rofecoxib - Diffusion of innovations -

New drugs $\cdot$ Patient characteristics

\section{Introduction}

Reasons for general practitioners (GPs) to prescribe new drugs may vary from an ongoing pursuit of alternative therapies for patients refractory to existing medications to a plethora of erratic market forces such as industry promotion and reimbursement. In an 'ideal' world, each prescribing decision would be based on careful weighing of the benefits, risks and costs of the new medicine in the context of alternative options. Various studies have focused on quantification and characterisation of doctors responsible for early prescriptions of a new drug [1]. To date little attention has been paid to socio-demographic characteristics of the first patients to receive new drugs. We chose the introduction of rofecoxib to study such patient factors. Rofecoxib was launched in The Netherlands for the symptomatic treatment of osteoarthritis in November 1999. The aim of this study was to identify early users of rofecoxib by socio-demographic characteristics. The reason for choosing rofecoxib was that we expected to find the influence of patients on the decision to prescribe to be because of its marketing and similarity to the existing non-steroidal anti-inflammatory drugs (NSAIDs) [2]. We hypothesised that patients with higher social economic status were more likely to have rofecoxib prescribed.

\section{Methods}

We obtained data from the Second Dutch National Survey of General Practice conducted by the Netherlands Institute of Health Services Research (NIVEL) in a representative sample of 195 Dutch GPs in 104 practices and 385,461 listed patients in 2001 [3]. These data provided background information on practice, GP, and 
patient level, including prescription data. Patient data included socio-demographic factors such as educational status, type of insurance and self-reported health. Patients were asked to rank their health on a five-point scale ranging from 'very bad' to 'very good'. For educational status, we used the highest completed level of education.

The prescription database contained 57,381 NSAID users. We compared the starters on rofecoxib $(n=954)$ with patients starting on other non-selective cyclo-oxygenase inhibitor NSAIDs $(n=25,231)$. Starters were defined as patients who had not received a prescription for a NSAID during the 90 days prior to starting on either rofecoxib or another NSAID.

Logistic regression was applied to estimate the prevalence odds ratios (including $95 \% \mathrm{CI}$ ) of characteristics in patients starting on rofecoxib compared with patients starting other NSAIDs.

\section{Results}

In total, 99 GPs working in 101 practices prescribed rofecoxib during the study period. We noted that rofecoxib starters were more likely to be elderly [OR for those aged 80 years and older 8.7 (6.7-11.2) and patients with a poor self-perceived health (OR 2.4; 1.8-3.3)]. Furthermore, rofecoxib starters were more frequently female (OR 1.4; 95\% CI 1.2-1.6), privately insured (OR
$=1.3 ; 1.1-1.5)$ or previous acetaminophen users $(\mathrm{OR}=1.3 ; 1.1-1.7)$. Moreover, start of treatment with rofecoxib was also seen more frequently in patients with a higher education, although this association diminished after adjustment for other variables (Table 1).

\section{Discussion}

Immediately following product launch, the diffusion of rofecoxib among prescribers showed a steep adoption curve. There has been ample public debate about the effectiveness and safety of rofecoxib. Concerns regarding cardiovascular safety in high-risk patients, in particular in the elderly with poor health and other co-morbidity, have evolved [4]. However, our data show that rofecoxib was preferentially prescribed to such patients. In previous studies, we have identified patterns of 'channelling' of NSAIDs in susceptible patients as threats to patient safety [5]. Industry promotion of the preferable profile of the new drug, in particular for patients with a poor response to existing therapies, is an important factor [6]. Although direct-to-consumer advertisement is prohibited in The Netherlands, the role of patients should not be underestimated. GPs have reported that patients often request rofecoxib in particular [6]. Our data show that private insurance is associated with receiving rofecoxib, but this only partly supports our hypothesis about patients with a higher social economic status

Table 1 Rofecoxib starters compared with other non-steroidal anti-inflammatory drug (NSAID) starters. Prevalence (\%) and results of logistic regression analyses expressed as crude and adjusted odds ratios (OR) and $95 \%$ confidence intervals (95\% CI)

\begin{tabular}{|c|c|c|c|c|c|c|}
\hline & \multicolumn{2}{|c|}{$\begin{array}{l}\text { Rofecoxib starters } \\
(n=954)\end{array}$} & \multicolumn{2}{|c|}{$\begin{array}{l}\text { NSAID starters } \\
(n=25,231)\end{array}$} & \multirow[t]{2}{*}{ Crude OR $(95 \% \mathrm{CI})$} & \multirow[t]{2}{*}{ Adjusted OR $(95 \% \mathrm{CI})^{a}$} \\
\hline & No. & Percentage & No. & Percentage & & \\
\hline \multicolumn{7}{|l|}{ Gender } \\
\hline Male & 321 & 33.6 & 11,303 & 44.8 & 1.0 & 1.0 \\
\hline Female & 633 & 66.4 & 13,928 & 55.2 & $1.6(1.4-1.8)$ & $1.4(1.2-1.6)$ \\
\hline \multicolumn{7}{|l|}{ Age (years) } \\
\hline $65-79$ & 309 & 32.4 & 3,706 & 14.7 & $6.3(5.1-7.7)$ & $5.5(4.4-6.8)$ \\
\hline $80+$ years & 150 & 15.7 & 997 & 4.0 & $11.3(8.9-14.4)$ & $8.7(6.7-11.2)$ \\
\hline \multicolumn{7}{|l|}{ Insurance } \\
\hline Public & 668 & 70.0 & 18,496 & 73.3 & 1.0 & 1.0 \\
\hline Private & 286 & 30.0 & 6,735 & 26.7 & $1.2(1.0-1.4)$ & $1.3(1.1-1.5)$ \\
\hline \multicolumn{7}{|l|}{ Educational status } \\
\hline Good & 384 & 40.3 & 1,3141 & 52.1 & 1.0 & 1.0 \\
\hline Moderate & 292 & 30.6 & 4,255 & 16.9 & $2.3(2.0-2.7)$ & $1.7(1.4-2.0)$ \\
\hline Poor & 63 & 6.6 & 653 & 2.6 & $3.3(2.5-4.4)$ & $2.4(1.8-3.3)$ \\
\hline Unknown & 215 & 22.5 & 7,182 & 28.5 & $1.0(0.9-1.2)$ & $1.2(0.9-1.7)$ \\
\hline \multicolumn{7}{|c|}{ Previous use of acetaminophen } \\
\hline No & 862 & 90.4 & 24,245 & 96.1 & 1.0 & 1.0 \\
\hline Yes & 92 & 9.6 & 986 & 3.9 & $2.6(2.1-3.3)$ & $1.3(1.1-1.7)$ \\
\hline
\end{tabular}

${ }^{a}$ Mutually adjusted 
being more likely to start on rofecoxib. The finding that previous acetaminophen use was associated with starting on rofecoxib may be explained by the wish of GPs to provide gastroprotection. In the Dutch healthcare system, privately insured patients, about $25 \%$ of the population, have a higher income, but are frequently not fully insured unless under various co-payment schemes. The reimbursement of rofecoxib is not limited to any type of insurance, age category or indication.

In conclusion, we found that specific patient characteristics were associated with receiving a prescription for rofecoxib shortly after marketing. GPs should be aware of selectively prescribing new drugs to specific patients because it may place patients at unintentional and avoidable risk.

Acknowledgements Data collection was mainly funded (directly and indirectly) through unrestricted grants by the Dutch Ministry of Health, Welfare, and Sports. Moreover, the "Stichting Centraal Fonds Reserves Voormalige Vrijwillige Ziektekostenverzekering" funded part of data collection. The Scientific Institute of Dutch
Pharmacists and a Ph.D. fellowship from The Danish University of Pharmaceutical Sciences funded the data analyses.

\section{References}

1. Inman W, Pearce G (1993) Prescriber profile and post-marketing surveillance. Lancet 342(8872):658-661

2. Cutts C, LaCaze A, Tett S (2002) A clinical audit of the prescribing of celecoxib and rofecoxib in Australian rural general practice. Br J Clin Pharmacol 54(5):522-527

3. Westert $\mathrm{G}$ et al (2005) Monitoring health inequalities through general practice: the second Dutch national survey of general practice. Eur J Publ Health (in press)

4. Boers M (2001) NSAIDS and selective COX-2 inhibitors: competition between gastroprotection and cardioprotection. Lancet 357(9264):1222-1223

5. Leufkens HG et al (1992) Channelling of controlled release formulation of ketoprofen (Oscorel) in patients with history of gastrointestinal problems. $\mathbf{J}$ Epidemiol Commun Health 46(4):428-432

6. Prosser H, Almond S, Walley T (2003) Influences on GPs' decision to prescribe new drugs - the importance of who says what. Fam Pract 20(1):61-68 